\title{
Uji Validitas dan Reliabilitas Konstruk Resiliensi Ego Menggunakan SEM
}

\author{
Rahmah Fitroh, Hadi Suyono \\ Universitas Ahmad Dahlan, Yogyakarta \\ Email: rahmahfitroh16@gmail.com
}

\begin{abstract}
The purpose of this study was to examine the validity and reliability of the ego resilience construct using SEM. The subjects of this stuudy were vocational high school students in Martapura who tested 149 students. The research scale uses ego resilience scale made by researchers developing from Shin and Park (2013). The scale is arranged based on a scale based on its aspects consisting of 24 statements with 4 alternative answer choices. The scale was analyzed using Sem AMOS software version 24. The result showed that 10 statements were valid and reliable.
\end{abstract}

Keywords: Ego resilience, validity, reliability, SEM

\begin{abstract}
Abstrak
Tujuan penelitian ini adalah untuk menguji validitas dan reliabilitas konstruk resiliensi ego menggunakan SEM. Subjek penelitian ini adalah siswa SMK di Martapura yang berjumlah 149 siswa. Skala penelitian menggunakan skala resiliensi ego yang dibuat sendiri oleh peneliti menegembangkan dari Shin dan Park (2013). Skala disusun berupa skala likert berdasarkan aspek-aspeknya yang berjumlah 24 pernyataan dengan 4 alternatif pilihan jawaban. Skala dianalisis menggunakan SEM software AMOS versi 24. Hasil penelitian menunjukkan bahwa terdapat 10 pernyataan yang valid dan reliabel.
\end{abstract}

Kata kunci: Resiliensi ego, validitas, reliabilitas, SEM

\section{Pendahuluan}

Pada masa remaja individu mengalami masa transisi yang signifikan, hal ini perlunya individu mampu menyesuaikan diri baik secara fisik, sosial dan emosional (Alessandri, Eisenberg, Vecchione, Capara \& Milioni, 2016). Perpindahan dari SMP ke SMA merupakan salah satu transisi utama yang dihadapi pada masa remaja. Memasuki sekolah menengah membutuhkan seperangkat aturan pembelajaran dan nilai baru, memperoleh peran sosial baru dan yang terpenting mempelajari mata pelajaran baru dan sering kali menantang (Alessandri, Zuffianỏ, Eisenberg \& Pastorelli, 2017). Taylor dan Jones (2019) memaparkan bahwa salah satu yang mencerminkan bagaimana individu mampu beradaptasi dengan stressor lingkungan dan mampu bertahan dengan perubahan yang berkaitan dengan penyesuaian yaitu dengan memiliki resiliensi ego. Hal ini sejalan dengan yang dipaparkan oleh Alessandri, De-Longis, Eisenberg, dan Hobfoll (2020) bahwa sumber daya pribadi merupakan kunci untuk dapat melindungi efek buruk dari stressor sehari-hari. Hasil penelitian menunjukkan bahwa Individu yang memiliki resiliensi ego mampu mengatasi kesulitan dalam hidup dan menjadi individu yang lebih kuat dengan adanya kesulitan tersebut (Ogelman \& Erol, 2015). Individu yang memiliki resiliensi ego tinggi dianggap sebagai kemampuan yang lebih fleksibel untuk manajemen stres (Omori \& Yoshioka, 2016). Selain itu, individu mampu beradaptasi degan cepat terhadap stressor eksternal, hal ini diharapkan bahwa individu mampu mengatasi secara efektif dan fleksibel dengan perubahan dan kesulitan. Temuan lain menyatakan bahwa resiliensi ego mampu memprediksi penyelesaian masalah yang efektif dalam situasi stres (Farkas \& Orosz, 2015). Elzohary, Mekhail, Hasan dan Manessy (2017) menambahkan bahwa resiliensi ego merupakan faktor perisai yang memandu individu untuk berhasil dalam peristiwa yang membingungkan dan mengurangi dari kondisi yang mengancam. Penelitian lain menemukan bahwa program peningkatan hubungan interpersonal dapat meningkatkan resiliensi ego yaitu dengan meningkatkan kesadaran positif remaja untuk membantu mengatasi situasi yang berbeda dan untuk melakukan strategi koping (Yeun \& Woo, 2018). Pentingnya peserta didik dilatih untuk mengembangkan resiliensi ego karena akan memberikan pengaruh pada saat dewasa, hal ini disebabkan bahwa resiliensi ego memiliki persepsi yang lebih baik dalam penyesuaian perilaku individu terhadap tuntutan sosial di berbagai situasi yang akan dihadapinya (Isler, Liu, Sibley \& Fletcher, 2016). Hal ini di dukung dengan hasil penlitian yang dilakukan oleh Taylor, Ruiz dan Nair (20118) bahwa resiliensi ego memiliki korelasi yang positif dengan keberhasilan akademik. Peserta didik yang memiliki tingkat resiliensi ego yang tinggi akan memiliki keterlibatan akademik yang tinggi. Salah satu aspek resiliensi

Diterima Redaksi : 23-03-2020 | Selesai Revisi : 05-05-2020 | Diterbitkan Online : 01-06-2020 
ego adalah optimis, dimana optimis memiliki efek moderasi yang signifikan terhadap peserta didik, hasil penelitian yang dilakukan oleh (Sung-Bong, Na-Mi, \& Jin-Suk, 2017) menyatakan bahwa optimisme remaja harus ditingkatkan untuk mengurangi tekanan akademik dan memastikan peserta didik sukses dalam kehidupan sekolah. Selain itu, perlunya mengembangkan intervensi dan program untuk mengurangi stres akademik dan meningkatkan resiliensi ego dalam meningkatkan kesehatan pada siswa (Ji-Hyun \& Eun-Hee, 2017). Oleh karena itu pentingnya pengembangan konstruk resiliensi ego sebagai kontruk dalam berbagai multidisiplin ilmu. Sebagaimana tujuan penelitian ini adalah untuk menguji konstruk resiliensi ego dengan menguji validitas dan reliabilitas yang belum teruji. Penelitian ini didukung dengan penelitian terdahulu yang membahas uji validitas dan reliabilitas skala resiliensi ego seperti yang dilakukan oleh (Chen, He \& Fan, 2019) dimana menguji validitas skala resiliensi ego pada budaya Cina dengan jumlah sampel 943 individu. Analisis skala menggunakan analisis faktor eksploratori (EFA), analisis faktor konfirmatori (CFA), dan estimasi reliabilitas. Hasil analisis menunjukkan skala resiliensi ego memiliki karakteristik psikometik yang baik untuk digunakan sebagai alat penilaian untuk tingkat ketahanann ego remaja Cin. Selain itu, penelitian yang dilakukan oleh (Farkas \& Orosz) yaitu menguji keandalan, validitas struktural dan konvergen pada skala resiliensi ego. Hasil penelitian menunjukkan bahwa resiliensi ego berfungsi yaitu untuk menjaga sistem kepribadian yang stabil dan utuh, untuk menyesuaikan sistem kepribadian dengan cara adaptif dengan lingkungan yang berubah secara dinamis. Penelitian lainnya yang sejalan dengan penelitian ini adalah penelitian yang dilakukan oleh (Vecchio, Baaracaccia, Raciti, Vera \& Milioni, 2018) dengan mengukur seiliensi ego pada komunitas dengan sampel penelitian berjumlah 947 individu. Analisis penelitian menggunakan CFA, dengan hasil penelitian menunjukkan bahwa skala resiliensi ego cocok ditujukan pada individu yang kurang beruntung (individu yang tinggal di empat belas aula kota dan individu yang dalam situasi kemiskinan ekstrem atau korban kekerasan).

\section{Metode Penelitian}

\subsection{Sampel dan Alat Ukur}

Sampel penelitian ini adalah siswa SMK di Martapura yang berjumlah 149 siswa, yang terdiri dari kelas X-XII. Alat ukur menggunakan skala resiliensi ego yang dibuat sendiri oleh peneliti dengan skala likert yang berjumlah 24 pernyataan. Skala resiliensi ego dibuat mengacu pada teori yang dikembangkan oleh Shin dan Park (2013) berdasarkan aspek-aspek resiliensi ego yang terdiri dari hubungan interpersonal, curiosity, kontrol emosi, optimis dan acticity. Pada penelitian ini hanya menggunakan 4 aspek, berikut merupakan blue print konstruk resiliensi ego:

Tabel 1.Tabel Blue Print Konstruk Resiliensi Ego

\begin{tabular}{|c|c|c|c|c|}
\hline \multirow{2}{*}{ Aspek } & \multirow{2}{*}{ Indikator } & \multicolumn{2}{|c|}{ No Item } & \multirow{2}{*}{ Jumlah } \\
\hline & & Favorable & Unvaforable & \\
\hline \multirow{3}{*}{$\begin{array}{l}\text { Hubungan } \\
\text { Interpersonal }\end{array}$} & $\begin{array}{l}\text { Senang berkumpul sambil berbagi cerita dengan } \\
\text { teman-teman }\end{array}$ & 1 & 13 & 2 \\
\hline & $\begin{array}{l}\text { Nyaman dengan teman, ketika yang dibicarakan } \\
\text { nyambung }\end{array}$ & 5 & 17 & 2 \\
\hline & Mudah akrab dengan orang lain & 19 & 21 & 2 \\
\hline \multirow{3}{*}{ Curiosity } & $\begin{array}{l}\text { Ketika ada materi pelajaran yang belum difahami, } \\
\text { bertanya dengan guru }\end{array}$ & 22 & 10 & 2 \\
\hline & Ketika galau, berusaha untuk mencari solusinya & 18 & 2 & 2 \\
\hline & $\begin{array}{l}\text { Belum faham dengan pelajaran yang diberikan } \\
\text { guru di sekolah, maka mempelajari di rumah }\end{array}$ & 14 & 6 & 2 \\
\hline \multirow{3}{*}{ Kontrol Emosi } & $\begin{array}{l}\text { Sabar ketika macet di jalan saat hendak pergi ke } \\
\text { sekolah }\end{array}$ & 7 & 23 & 2 \\
\hline & $\begin{array}{l}\text { Ketika badmood, pergi jalan-jalan bersama teman } \\
\text { Hasil ujian di skeolah mendapatkan nilai yang }\end{array}$ & 11 & 19 & 2 \\
\hline & $\begin{array}{l}\text { rendah, maka menerimanya tanpa menyalahkan } \\
\text { diri sendiri }\end{array}$ & 3 & 15 & 2 \\
\hline \multirow{3}{*}{ Optimis } & Yakin mampu mengerjakan ujian sekolah sendiri & 20 & 4 & 2 \\
\hline & $\begin{array}{l}\text { Ketika belajar dengan giat, bisa memahami } \\
\text { pelajaran di sekolah }\end{array}$ & 16 & 8 & 2 \\
\hline & $\begin{array}{l}\text { Pernah gagal menjadi siswa yang terbaik di kelas, } \\
\text { saya berjuang lagi agar menjadi yang terbaik }\end{array}$ & 24 & 12 & 2 \\
\hline & Total & 12 & 12 & 24 \\
\hline
\end{tabular}


Pada tabel 1 di atas, dapat dilihat bahwa konstruk resiliensi ego menggunakan 4 aspek pada penelitian ini, yang setiap aspek memiliki tiga indikator dengan total 24 indikator dan 24 total item yang terdiri dari 12 favorable dan 12 unfavorable.

\subsection{Prosedur}

Peneliti melakukan penelitian dengan menyebar skala pada siswa-siswi SMK di Martapura selama satu hari, yaitu pada tanggal 5 Desember 2019. Skala resiliensi ego menggunakan skala likert dengan 4 penilaian dan alternatif jawaban. Skala di isi oleh siswa berdasarkan pernyataan yang mendekati dengan diri siswa. Penilain skala berdasarkan jenis pernyataan yang dapat dilihat pada tabel 2 berikut ini:

Tabel 2.Tabel Penilain Skala

\begin{tabular}{lccc}
\hline \multicolumn{1}{c}{ Alternatif Jawaban } & & Favorable & Unfavorable \\
\hline Sangat Sesuai & (SS) & 4 & 1 \\
Sesuai & (S) & 3 & 2 \\
Tidak Sesuai & (TS) & 2 & 3 \\
Sangat Tidak Sesuai & (STS) & 1 & 4 \\
\hline
\end{tabular}

Analisis penelitian ini untuk menguji validitas dengan menghitung nilai Confirmatory Factor Analysis (CFA) menggunakan software Structural Equation Modelling (SEM) AMOS versi 24. Uji validitas adalah untuk mengukur korelasi antar item skala penelitian dengan konstruk penelitian yaitu melihat nilai loading factor atau standardized loading estimate. Uji validitas yang memenuhi nilai loading factor $>0,5$ maka dinyatakan valid (Ghozali, 2017). Uji reliabilitas pada penelitian ini dengan menghitung nilai Average Variance Extracted (AVE) dengan nilai Construct Reliability (CR). Penilaian yang direkomendasikan pada uji ini yaitu memiliki nilai AVE >0,5 maka dinyatakan valid dan dikatakan reliabel jika nilai CR >0,7 (Ghozali, 2017). Berikut merupakan cara menentukan nilai AVE pada rumus 1 dan nilai CR pada rumus 2:

$$
\begin{aligned}
& A V E=\frac{\sum_{i=1}^{n} \lambda i^{2}}{\sum_{i=1}^{n} \lambda i^{2}+\sum_{i=1}^{n} \operatorname{Var}(\varepsilon i)} \\
& A V E=\frac{\left[\sum_{i=1}^{n} \lambda i\right]^{2}}{\left[\sum_{i=1}^{n} \lambda i\right]^{2}+\left[\sum_{i=1}^{n} \delta i\right]}
\end{aligned}
$$

\section{Hasil dan Pembahasan}

\subsection{Uji Validitas}

Hasil perhitungan uji validitas menggunakan nilai CFA, item yang memiliki nilai loading factor $>0,5$ dapat dilihat pada tabel berikut:

Tabel 3.Tabel Nilai CFA

\begin{tabular}{cccc}
\hline Aspek & Kode Item & Loading Factor & Keterangan \\
\hline \multirow{3}{*}{ Hubungan Interpersonal } & RE1 & $-0,008$ & Tidak Valid \\
& RE5 & $-0,81$ & Tidak Valid \\
& RE9 & 0,772 & Valid \\
& RE13 & 0,093 & Tidak Valid \\
& RE17 & $-0,63$ & Tidak Valid \\
& RE21 & 0,0770 & Valid \\
& RE2 & $-0,72$ & Tidak Valid \\
Curiosity & RE6 & 0,765 & Valid \\
& RE10 & 0,882 & Valid \\
& RE14 & 0,847 & Tidak Valid \\
& RE18 & $-0,178$ & Tidak Valid \\
& RE22 & $-0,72$ & Tidak Valid \\
& RE3 & 0,005 & Tidak Valid \\
& RE7 & 0,021 & Valid \\
& RE11 & 0,803 & Tidak Valid \\
& RE15 & $-0,127$ & Tidak Valid \\
& RE19 & $-0,016$ & Valid
\end{tabular}

Psyche 165 Journal Terakredetasi Sinta 5 


\begin{tabular}{cccc} 
& RE4 & 0,851 & Valid \\
RE8 & 0,140 & Tidak Valid \\
Optimis & RE12 & 0,038 & Tidak Valid \\
& RE16 & 0,097 & Tidak Valid \\
& RE20 & 0,792 & Valid \\
RE24 & 0,818 & Valid \\
\hline
\end{tabular}

Bersarkan pada tabel 3 di atas dapat dilihat bahwa terdapat 10 item yang memiliki loading factor $>0,5$ maka dinyatakan valid dan terdapat 14 item yang memiliki nilai loading factor $<0,5$ maka dinyatakan tidak valid. Berikut output uji validitas skala resiliensi ego setelah estimasi ulang dapat dilihat pada tabel 3 di bawah ini:

Tabel 4.Nilai CFA Setelah Estimasi Ulang

\begin{tabular}{cccc}
\hline Aspek & Kode Item & Loading Factor & Keterangan \\
\hline \multirow{2}{*}{ Hubungan Interpersonal } & RE9 & 0,769 & Valid \\
& RE21 & 0,766 & Valid \\
Curiosity & RE6 & 0,765 & Valid \\
& RE10 & 0,823 & Valid \\
Kontrol Emosi & RE14 & 0,846 & Valid \\
& RE11 & 0,801 & Valid \\
& RE23 & 0,840 & Valid \\
Optimis & RE4 & 0,849 & Valid \\
& RE20 & 0,794 & Valid \\
& RE24 & 0,817 & Valid \\
\hline
\end{tabular}

Berdasarkan pada tabel 4 di atas dapat dilihat bahwa setelah melakukan estimasi ulang 10 item dinyatakan valid yaitu $>0,5$. Berikut merupakan hasil analisis 2nd order CFA konstruk resiliensi ego:

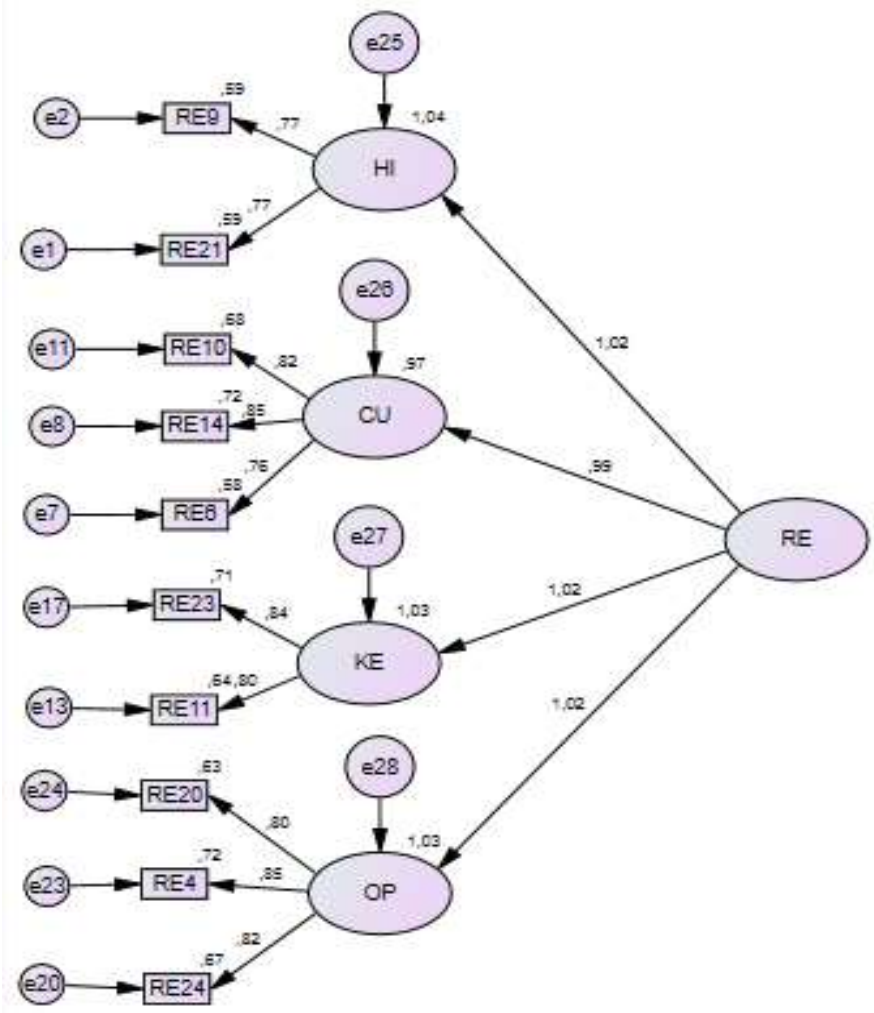

Gambar 1. Nilai 2nd order CFA Konstruk Resiliensi Ego 
Tabel 5.Nilai 2nd Order CFA

\begin{tabular}{lccc}
\hline \multicolumn{1}{c}{ Aspek } & & Loading Factor & Keterangan \\
\hline Hubungan Interpersonal & $(\mathrm{HI})$ & 1,02 & Valid \\
Curiosity & $(\mathrm{CU})$ & 0,99 & Valid \\
Kontrol Emosi & $(\mathrm{KE})$ & 1,02 & Valid \\
Optimis & $(\mathrm{OP})$ & 1,02 & Valid \\
\hline
\end{tabular}

Hasil analisis yang dapat di lihat pada output SEM pada gambar 1 dan kesimpulan gambar pada tabel 5 menunjukkan bahwa aspek hubungan interpersonal, curiosity, kontrol emosi, dan optimis memiliki nilai loading factor $>0,5$ maka dinyatakan valid dan aspek-aspek tersebut mengukur konstruk resiliensi ego.

\subsection{Uji Reliabilitas}

Hasil perhitungan AVE, dengan nilai $>0,5$ dan CR dengan nilai >0,7 dapat dilihat pada tabel berikut:

Tabel 6. Nilai AVE dan CR

\begin{tabular}{cccc}
\hline Konstruk & AVE & CR & Keterangan \\
\hline Resiliensi Ego & 0,924 & 0,949 & Reliabel \\
\hline
\end{tabular}

Pada tabel 6 dapat dilihat bahwa nilai AVE 0,924 dan CR 0,949 maka konstruk resiliensi ego dinyatakan reliabel.

\subsection{Blue Print Resiliensi Ego Setelah Renumerisasi}

Skala resiliensi ego di lakukan renumerisasi ulang agar skala siap digunakan untuk penelitian, dapat dilihat pada tabel berikut:

Tabel 7. Blue Print Resiliensi Ego Setelah Renumerisasi

\begin{tabular}{|c|c|c|c|c|}
\hline \multirow{2}{*}{ Aspek } & \multirow{2}{*}{ Indikator } & \multicolumn{2}{|c|}{ No Item } & \multirow{2}{*}{ Jumlah } \\
\hline & & Favorable & Unvaforable & \\
\hline \multirow{2}{*}{$\begin{array}{l}\text { Hubungan } \\
\text { Interpersonal }\end{array}$} & Mudah akrab dengan orang lain & 3 & 7 & 2 \\
\hline & $\begin{array}{l}\text { Ketika ada materi pelajaran yang belum difahami, } \\
\text { bertanya dengan guru }\end{array}$ & - & 4 & 1 \\
\hline \multirow[t]{2}{*}{ Curiosity } & $\begin{array}{l}\text { Belum faham dengan pelajaran yang dierikam } \\
\text { guru di sekolah, maka mempelajari di rumah }\end{array}$ & 5 & 2 & 2 \\
\hline & $\begin{array}{l}\text { Sabar ketika macet di ajlan saat hendak pergi ke } \\
\text { sekolah }\end{array}$ & 8 & - & 1 \\
\hline \multirow{2}{*}{ Kontrol Emosi } & Ketika badmood, pergi jalan-jalan bersama teman & 10 & - & 1 \\
\hline & Yakin mampu mengerjakan ujian sekolah sendiri & 6 & 1 & 1 \\
\hline \multirow[t]{2}{*}{ Optimis } & $\begin{array}{l}\text { Pernah gagal menjadi siswa yang terbaik di kelas, } \\
\text { saya berjuang lagi agar menjadi yang terbaik }\end{array}$ & 9 & - & 1 \\
\hline & Total & 6 & 4 & 10 \\
\hline
\end{tabular}

Pada tabel 7 di atas dapat dilihat blue print konstruk resiliensi ego setelah renumerisasi yang terdiri dari 10 pernyataan, 6 pernyataan favorable dan 4 pernyataan unfavorable.

\section{Kesimpulan}

Hasil uji validitas dan reliabilitas menggunakan SEM AMOS versi 24 dapat disimpulkan bahwa konstruk resiliensi ego valid dan reliabel dengan skala yang dibuat sendiri oleh peneliti, maka dapat digunakan untuk mengukur resiliensi ego pada siswa. Resiliensi ego memiliki 5 aspek, akan tetapi pada penelitian ini hanya mengunakan 4 yang mencerminkan pada diri subjek yang diteliti. Aspek resiliensi ego diantaranya hubungan interpersonal, curiosity, kontrol emosi dan optimis. Aspek-aspek tersebut mampu mengukur konstruk resiliensi ego. Hasil pengujian maka didapatkan 10 item yang dapat digunkan pada penelitian selanjutnya. 


\section{Daftar Rujukan}

Alessandri, G., Eisenberg, N., Vecchione, M., Caprara, G.V., \& Milioni, M. 2016. Ego-resiliency development from late adolescence to emerging adulthood: A ten-year longitudinal study. Journal of Adolescence, 50 (1), 91-102.

Alessandri, G., Zuffianỏ, A., Eisenberg, N., \& Pastorelli, C. 2017. The role of ego-resiliency as mediator of the longitudinal relationship between family socio-economic status and school grades. Journal of Youth and Adolescence, 46 (1), 2157-2168.

Taylor Z.E., \& Jones, B.L. 2019. Cultural contributors to ego-resiliency and associations with depressive problems in Midwestern Latino youth. Journal of Research on Adolescence, 30 (2). 349-361.

Alessandri, G., De Longis, E., Eisenberg, N., \& Hobfoll, S.E. 2020. A multilevel moderated mediational model of the daily relationships between hassles, exhaustion, ego-resiliency and resulting emotional inertia. Journal of Research in Personality, 103913, 1-42.

Ogelman, H.G., \& Erol, A. 2015. Examination of the predicting effect of the resiliency levels of parents on the resiliency levels of oreschool children. Procedia-Social and Behavioral Sciences, 186 (1). 461-466.

Omori, M., \& Yohika, S. 2016. Comparisons of emotional intelligence, mental health and ego-resilience between mothers of children/adolescents with and without disabilities. Shimane J. Med. Sci, 33 (1). 17-25.

Farkas, D., \& Osrossz, G. 2015. Ego-resiliency reloaded: A three-component model of general resiliensy. PloS ONE, 10 (3). 1-26.

Elzohary, N.W., Mekhail, M.N., Hassan, N.I., \& Menessy, R.F.M. 2017. Relationship between ego resilience, perceived stress and life satisfaction among faculty nursing students. IOSR Journal of Nursing and Health Science (IOSR-JNHS), 6 (6). 57-70.

Yeun, Y.R., \& Woo, H.Y. 2018. The effects of an interpersonal relationship inprovement program on self-esteem, interpersonal orientation, and ego-resilienceon Korea adolescents. Biomedical Research, 29 (20). 3701-3703.

Isler, L., Liu, H., Sibley, C.G., \& Fletcher, G.J.O. 2016. Self-regulation and personality profiles: Empirical development, longitudinal stability and predictive ability. European Journal of Personality, 30 (1). $274-287$.

Taylor, Z.E., Ruiz, Y., \& Nair, N. 2018. A mixed-method examination of ego-resiliency, adjustment problems, and academic engagment in children of Latino migrant farmworkers. Social Development.

Sug-Bong, K., Na-Mi, S., \& Jin-Suk, K. 2017. Moderating effects of ego-resilience on the relationship between academic stress and school adjustment of adolescent. Journal of the Korea Academia-Industrial Cooperation Society, 18 (8). 145-151.

Ji-Hyun, P., \& Eun Hee, K. 2017. Relationship of academic stress, ego-resilience and health promoting behaviors in nursing students. Journal of the Korea Academia-Industrial Cooperation Society, 18 (9). 193-202.

Chen, X., He, J., \& Fan, X. 2019. Applicability of the Ego-Resilience Scale (ER89) in the Chinese cultural context: A validation study. Journal of Psychoeducational Assessment. 1-17.

Vecchio, G. M., Baracaccia, ., Raciti, P., Bera, P. V., \& Milioni, M. 2018. Validation of the revised ego-resiliency scale in a high-vulnerable colombian population. Universitas Psychologia, 18 (3). 1-13.

Shin, E.J., \& Park, Y.S. 2013. Emotional intelligences, ego resilience, stress in clinical practice of nursing students. Journal of the Korea Academia-Industrial, 14 (11). 5636-5645.

Ghozali, I. 2017. Model persamaan struktural konsep dan aplikasi dengan program amos 24. Edisi 7. Semarang: Badan Penerbit- Undip. 